RAD Conference Proceedings, vol. 2, pp. 85-89, 2017

www.rad-proceedings.org

20.0001 tht

\title{
MONITORING OF LONG TERM RF RADIATION FROM CELLULAR BASE STATIONS
}

\author{
Çetin Kurnaz*, Begüm Korunur Engiz, Ahmet Turgut \\ Ondokuz Mayıs University, Engineering Faculty, \\ Department of Electrical and Electronics Engineering, Samsun, Turkey
}

\begin{abstract}
In parallel with technological developments, cellular systems and therefore base stations have begun to take up more space in our daily lives. Since each base station behaves like a radiofrequency electromagnetic field ( $R F-$ $E M F)$ source, this increase in base stations leads to an increase in the value of RF-EMF. Therefore, it is very important to measure and evaluate the RF-EMF emitted from the base stations regarding its influence on human health. In this study, RF-EMF measurements were taken in ten different locations (schools, hospitals, homes, shopping malls, etc.) during 24 hours to investigate the time/location dependent changes in RF-EMF. For the measurement, the PMM8053 EMF meter measuring the total RF-EMF in the frequency range of $100 \mathrm{kHz}-3 \mathrm{GHz}$ was used, the highest electric field strengths $\left(E_{\max }\right)$ in the environment and the average electric field strengths $\left(E_{\text {avg }}\right)$ were recorded. The measurement results show that the electric field strengths (E) originating from the base stations change significantly depending on the measurement location and time (usage intensity). The changes in E measured during the daytime in the home environment are softer, while for workplaces they are sharper due to opening/closing time. It is seen from the measurements that the highest $E_{\max }$ is $7.88 \mathrm{~V} / \mathrm{m}$ and the highest $E_{\text {avg }}$ is $2.95 \mathrm{~V} / \mathrm{m}$. In order to analyze the 24-hour measurements more precisely, four specific time intervals such as morning (6am-12am), afternoon (12am-6pm), evening (6pm-12pm) and night (12pm-6am) were selected. The mean E value for morning is $1.55 \mathrm{~V} / \mathrm{m}$, while they are $1.94 \mathrm{~V} / \mathrm{m}, 1.48 \mathrm{~V} / \mathrm{m}$ and $1.16 \mathrm{~V} / \mathrm{m}$ for afternoon, evening and night respectively. $E$ level at night increases by $67.2 \%$ compared to in the afternoon. At the end of the study, daily variations of $E$ values were examined and empirical models were proposed using curve fitting methods. With the use of these models, the $E$ in the environment can be predicted with an accuracy of up to $95 \%$.
\end{abstract}

Key words: Electromagnetic field measurement, Electric field strength, PMM-8053, Base station, ICNIRP

DOI: $10.21175 /$ RadProc.2017.18

\section{INTRODUCTION}

Electromagnetic (EM) waves are radiated from many sources, both natural and man-made such as radio and TV transmitters, base stations, power lines, transformers, electrical household appliances, medical equipment, etc. that produce electromagnetic pollution. The growth of technological developments leads to an increase in the demand for wireless systems. The equipment that wireless systems use emits electromagnetic waves like any other electronic device, and their frequent use causes an increase in radiofrequency electromagnetic field (RF-EMF). In cellular systems that are a form of the wireless communication systems, users communicate to each other over base stations. In parallel with technological developments, there has been a dramatic growth in the use of cellular systems. Because each base station is an electromagnetic radiation source, with the increase in the number of base stations, exposed RF-EMF levels have also increased. Since each base station works within a limited geographical region and for a limited number of users, mobile system operators must install more base stations in order to meet a growing demand for multimedia services, and communication from any place. Although the wireless systems operate at frequencies below $300 \mathrm{GHz}$, which is within the nonionizing spectrum, an assessment of any health aspect of exposure to microwave emissions is needed. Measuring and evaluating the RF-EMF emitted by base stations and wireless systems, and controlling their compliance with standards/limit values is of great importance for human health and helps to take precautions. Therefore, many researches [1-9] have been focused on the measurement and assessment of electric field strength (E) that is emitted from wireless devices. Determining especially the change in emitted E levels from base stations depending on usage density at particular times of day has great importance.

Therefore, differently from the existing works, we evaluate the change in E levels within a day, based on 24-hour long-term measurements conducted at ten different locations using PMM 8053 EM field strength meter. Finally, detailed analyses of the measurement data were performed.

\footnotetext{
*ckurnaz@omu.edu.tr
} 


\section{Measurement of Electric Field Strength}

There are international standards and limits on the effects of RF-EMF on human health. The limits are recommended by the International Commission on Non-Ionizing Radiation Protection (ICNIRP), which is recognized by the World Health Organization (WHO). Each country has its own determined limits. The USA and some European countries use limits determined by the ICNIRP [10], while other European countries like Switzerland and Italy use $1 / 10$ of the ICNIRP's values as a limit. In Turkey, the regulations on exposure limits for EM fields are released by Information and Communication Technologies Authority of Turkey (ICTA) [11]. Turkey applies limits that are $75 \%$ of ICNIRP reference levels as endorsed by ICTA [11]. The limits of the electrical field are shown in Figure 1 based on ICNIRP and ICTA guidelines on exposure limits. The limits are given for exposure averaged over a sixminute interval. There are currently three mobile communication operators in Turkey and they use $2 \mathrm{G}$ (second generation), 3G (third generation) and $4 \mathrm{G}$ (fourth generation) systems. According to the [11], the limits are $30.9(\mathrm{~V} / \mathrm{m})$ for $900 \mathrm{MHz}$ base station, 43.7 $(\mathrm{V} / \mathrm{m})$ for $1800 \mathrm{MHz}$ base station, $45.75(\mathrm{~V} / \mathrm{m})$ for $3 \mathrm{G}$ systems, which is $2100 \mathrm{MHz}$, and also $45.75(\mathrm{~V} / \mathrm{m})$ for $2600 \mathrm{MHz}$ base station.

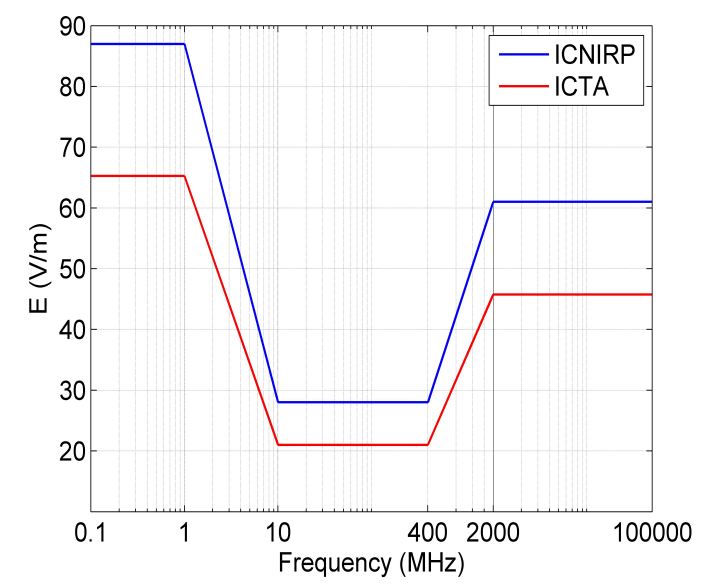

Figure 1. The ICNIRP and ICTA guideline for public exposures as a function of carrier frequency

In this study, in order to evaluate the change in $\mathrm{E}$ levels within a day, E measurements were conducted 24 hours a day with a fifteen-second sampling period at ten different locations (i.e. campus, school, hospital, pharmacy, apartment, shopping mall etc.) using PMM 8053 portable EMF strength meter with an EP-330 isotropic E-field probe [12]. Total $\mathrm{Es}$ in the band between $100 \mathrm{kHz}-3 \mathrm{GHz}$ (including FM, TV, GSM, UMTS and WLAN services) can be measured with PMM-8053. The measurements were performed between October 2015 and December 2016. Measurement locations are named as L1, L2, L3, L4, L5, L6, L7, L8, L9, L10, and displayed in Figure 2. L1 and L4 are outdoor measurement mediums while others are indoor mediums. There is a line of sight (LOS) between the base station and PMM 8053 in other locations except for L2 and L5.
L1

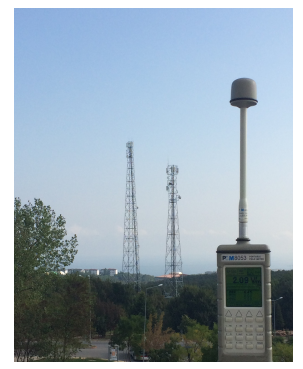

L3

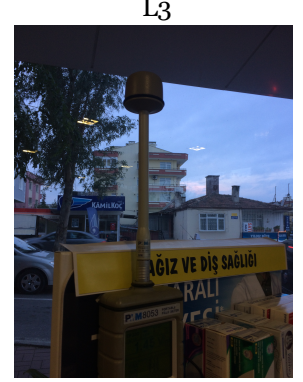

L5

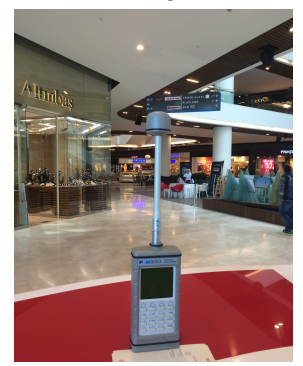

L7

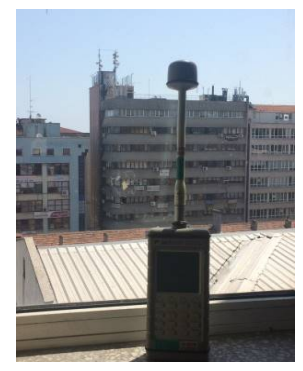

L9

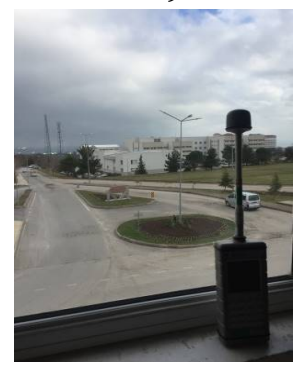

Figure 2. Pictures of E measurements at different locations

using PMM-8053 EM field meter

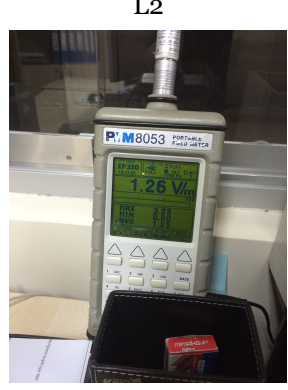

L4

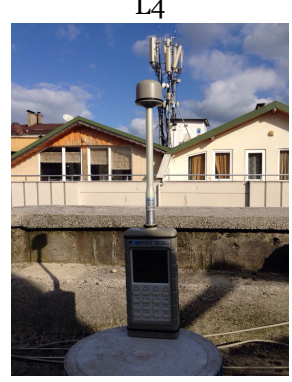

L6

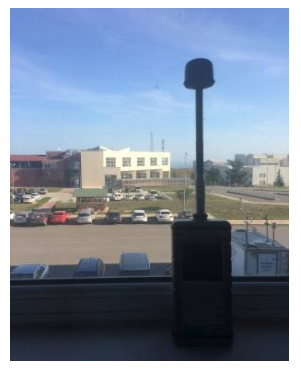

L8

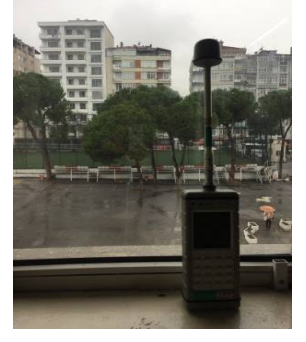

L10

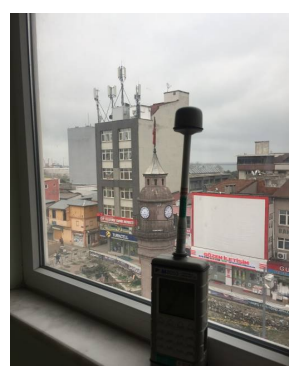




\section{Measurement Results}

The Es recorded during the 24-hour long-term measurements at ten different locations are given in Figure 3. It can be concluded from the evaluation of the measurement results that the measured E levels can vary with time depending on base station usage density and the number of active users. As seen from the results of L1 and L6 (on University Campus), a significant increase in $\mathrm{E}$ levels occurs during midday when the students are on campus and the base stations are used heavily. The E value decreased after 16:00 as students started to leave campus. Since constant visitors and patients are in service throughout the entire day, there are no sudden fluctuations in E for L2 (on a hospital), except between the hours of 04.0006.0o. Because L3 is conducted at a pharmacy, its opening and closing hours directly affect the measured $\mathrm{E}$ levels. The increase and the decrease in E levels occur accordingly to the working hours. For the case of L4, L7, L9 and L10 (an apartment), the E level dropped after 24:00 because the usage of the base station was lower. The change in E levels of L5 (a shopping mall) shows that a significant change occurs between 10.0022:00 when the shopping mall is open, the substantial decrease in E starts after 22:00 with the closing. For case L8 (a school) the E level decrease after 18:00 because the school is closed.
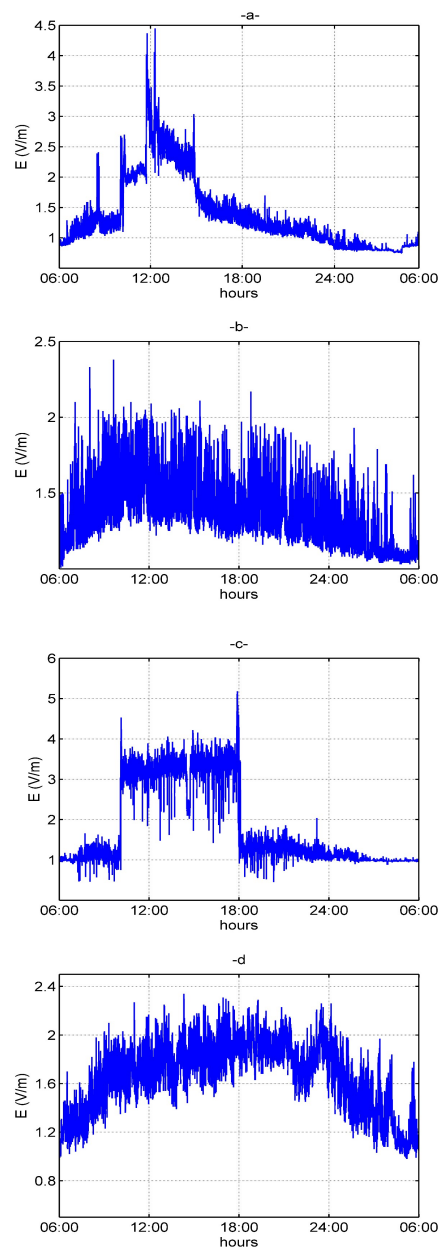
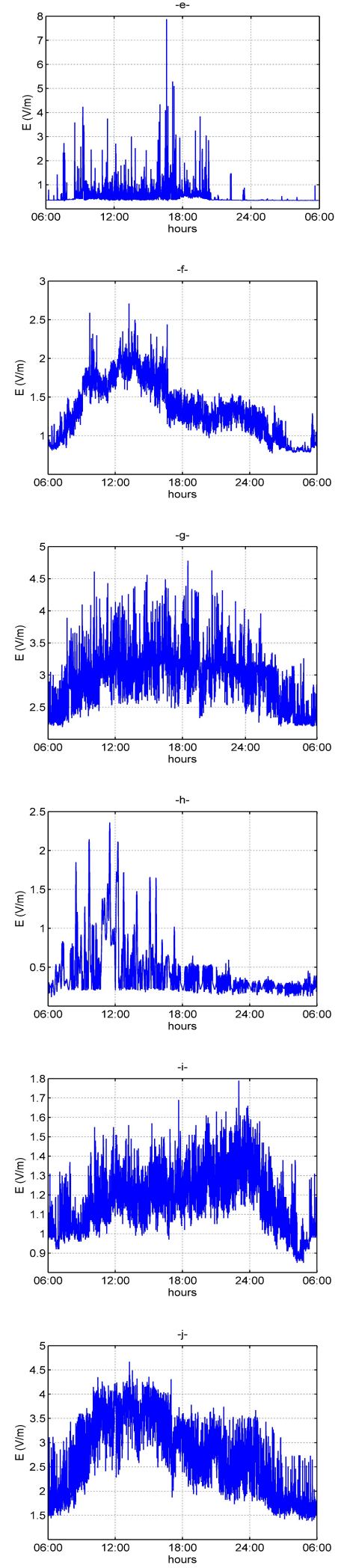

Figure 3. Measured E levels for a 24-hour period of a) L1, b) L2, c) L3, d) L4, e) L5, f) L6, g) L7, h) L8, i) L9, and j) L10 
The descriptive statistics of measurement results are tabulated in Table 1 . As seen from the table, the maximum $\mathrm{E}$ is $7.88 \mathrm{~V} / \mathrm{m}$ recorded in $\mathrm{L} 5$, while the maximum of the mean values (averaged over 24 hours) is reached at $\mathrm{L} 7$ as $2.95 \mathrm{~V} / \mathrm{m}$. The maximum standard deviation is also calculated as $1.04 \mathrm{~V} / \mathrm{m}$ for L3.

Table 1. Descriptive statistics of measurement results

\begin{tabular}{|c|c|c|c|}
\hline \multirow{2}{*}{$\begin{array}{c}\text { Measurement } \\
\text { Locations }\end{array}$} & \multicolumn{3}{|c|}{$\mathrm{E}(\mathrm{V} / \mathrm{m})$} \\
\cline { 2 - 4 } & Maximum & Mean & $\begin{array}{c}\text { Standard } \\
\text { Deviation }\end{array}$ \\
\hline L1 & 4.45 & 1.37 & 0.58 \\
\hline L2 & 2.38 & 1.37 & 0.22 \\
\hline L3 & 5.18 & 1.83 & 1.04 \\
\hline L4 & 2.34 & 1.65 & 0.29 \\
\hline L5 & 7.88 & 0.52 & 0.39 \\
\hline L6 & 2.71 & 1.34 & 0.37 \\
\hline L7 & 4.78 & 2.95 & 0.40 \\
\hline L8 & 2.36 & 0.43 & 0.32 \\
\hline L9 & 1.79 & 1.17 & 0.15 \\
\hline L10 & 4.67 & 2.7 & 0.77 \\
\hline
\end{tabular}

In order to analyze the 24-hour measurements more precisely, four specific time intervals such as morning (6 am-12 am), afternoon (12 am-6 pm), evening (6 pm-12pm) and night (12 pm-6 am) were selected. The mean $\mathrm{E}$ values for the specified intervals are calculated and given in Table 2. It can be seen from the table that higher $\mathrm{E}$ values are generally reached for the afternoon intervals. The minimum and the maximum values within these intervals are determined and the change is calculated from their ratio. The last column indicates the percentage of the change. It can be concluded from these results that the maximum change is obtained at L3 as $\mathbf{2 2 4 . 8 \%}$.

In order to evaluate and define the changes in the measured $\mathrm{E}$ levels better, the $\mathrm{E}$ values that were recorded at ten different locations were averaged over six minutes, then various curve-fitting methods were applied to data. The best fitting method is determined as second order Gaussian, considering both the simplicity and error performance. The performance of the method was compared in terms of Normalized Root Mean Square Error (NRMSE), which is defined by the following:

$$
\text { NRMSE }=\frac{\sqrt{\frac{1}{N} \sum_{i=1}^{N}\left(E_{i}-\hat{E}_{i}\right)^{2}}}{\max (E)-\min (E)}
$$

Where $E_{i}$ is the actual $E$ values, $\hat{E}_{i}$ is the estimated $\mathrm{E}$ values, $i$ is measurement time/sample, and $\mathrm{N}$ is the number of total measurement samples.
Table 2. The mean E values for the specified intervals

\begin{tabular}{|c|c|c|c|c|c|}
\hline \multirow{2}{*}{ 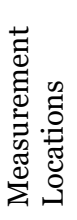 } & \multicolumn{5}{|c|}{$\mathrm{E}(\mathrm{V} / \mathrm{m})$} \\
\hline & . & 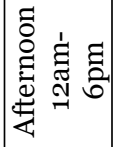 & 点 & 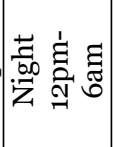 & Change \\
\hline L1 & 1.51 & 1.95 & 1.13 & 0.83 & $133 \%$ \\
\hline L2 & 1.47 & 1.46 & 1.37 & 1.17 & $25.9 \%$ \\
\hline $\mathrm{L}_{3}$ & 1.73 & 3.29 & 1.27 & 1.01 & $224.8 \%$ \\
\hline L4 & 1.52 & 1.82 & 1.86 & 1.39 & $34.2 \%$ \\
\hline L5 & 0.55 & 0.67 & 0.49 & 0.35 & $89.2 \%$ \\
\hline L6 & 1.38 & 1.73 & 1.27 & 0.94 & $82.9 \%$ \\
\hline $\mathrm{L} 7$ & 2.84 & $\mathbf{3 . 1 7}$ & 3.13 & 2.64 & $20.1 \%$ \\
\hline L8 & 0.60 & 0.54 & 0.30 & 0.24 & $46.9 \%$ \\
\hline L9 & 1.08 & 1.20 & 1.29 & 1.09 & $75.9 \%$ \\
\hline L10 & 2.73 & $\mathbf{3 . 4 7}$ & 2.65 & 1.93 & $79.7 \%$ \\
\hline
\end{tabular}

Based on the NMRSE values, the best fitting was obtained for L1 through Eq. 2, and the actual and the estimated $\mathrm{E}$ values were graphed in Fig. 4.

$$
\mathrm{E}(\theta)=1.146 \mathrm{e}^{-\left(\frac{\theta-66.97}{24.69}\right)^{2}}+1.263 \mathrm{e}^{-\left(\frac{\theta-90.88}{190.3}\right)^{2}}
$$

where $\mathrm{E}(\theta)$ is the estimated $\mathrm{E}$, and $\theta$ is the time index defined as following:

$$
\theta=1+\frac{\text { time }-06: 00}{6}
$$

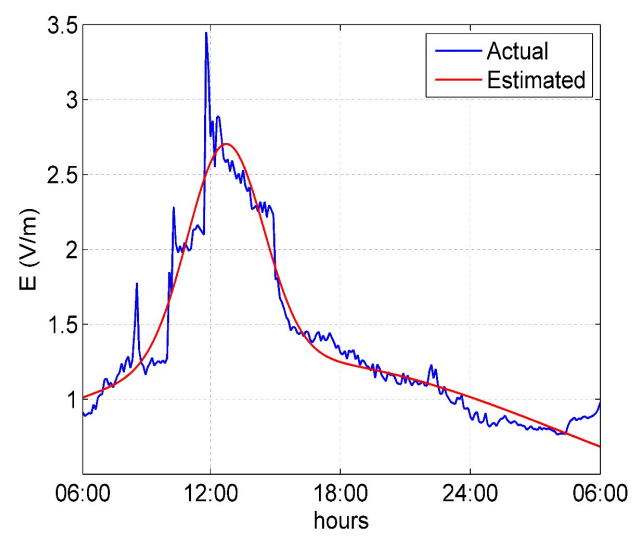

Figure 4. Actual and estimated E values for L1

The lowest NRMSE value between the actual and estimated E is calculated as 0.055 through Eq. 1 for L1. The same fitting method was applied to data that was recorded at the other locations. The NRMSE values for each measurement location are calculated and tabulated in Table 3. As seen from the table, NMRSE values are considerably higher for the places that have certain opening/closing times (L3, L8) than those calculated for residential/apartment areas. 
Table 3. The NRMSE values for each measurement location

\begin{tabular}{|c|c|}
\hline $\begin{array}{c}\text { Measurement } \\
\text { location }\end{array}$ & NRMSE \\
\hline L1 & 0.055 \\
\hline L2 & 0.097 \\
\hline L3 & 0.134 \\
\hline L4 & 0.087 \\
\hline L5 & 0.095 \\
\hline L6 & 0.079 \\
\hline L7 & 0.122 \\
\hline L8 & 0.138 \\
\hline L9 & 0.094 \\
\hline L10 & 0.089 \\
\hline
\end{tabular}

\section{CONCLUSIONS}

In this study, the changes in E levels within a day are evaluated based on 24-hour long-term measurements conducted at ten different locations. It is seen from the results that the measured E levels vary with the measurement location and time. As a result of base station usage density, the substantial increase is observed in E levels that were recorded especially in measurements during the day. The overall assessment of measurement results shows that the maximum $\mathrm{E}$ value is $7.88 \mathrm{~V} / \mathrm{m}$, while the mean and the standard deviation are $2.95 \mathrm{~V} / \mathrm{m}$ and $1.04 \mathrm{~V} / \mathrm{m}$ respectively. The evaluation of the measurement results shows that 224.8\% increase occurs in the E levels in the afternoon compared to those recorded at night. A new empirical model was proposed to estimate daily variations of $\mathrm{E}$ values. With the use of the proposed model, the $\mathrm{E}$ in the environment can be estimated up to $95 \%$ accuracy.

\section{REFERENCES}

1. Ç. Kurnaz, "An Empirical Modelling of Electromagnetic Pollution on an University Campus," The Applied Computational Electromagnetic Society Express Journal, vol. 1, no. 2, pp. 76 - 79, Feb. 2016. Retrieved from:

http://www.aces-

society.org/includes/downloadpaper.php?of=ACES Express Journal February 2016\&nf $=$ ej-16-2-full Retrieved on: Jan. 5, 2017

2. B. K. Engiz, Ç. Kurnaz, "Long-Term Electromagnetic Field Measurement and Assessment for a Shopping Mall," Radiation Protection Dosimetry, vol. 175, no. 3, pp. $321-329$, Nov. 2016.

DOI: $10.1093 / \mathrm{rpd} / \mathrm{ncw} 343$ PMid: 27885087

3. A. Mousa, "Electromagnetic radiation measurements and safety issues of same cellular base stations in Nablus," Journal of Engineering Science and Technology Review, vol. 4, no. 1, pp. 35 - 42, Feb. 2011.

Retrieved from:

http://www.jestr.org/downloads/volume4/fulltexto7 2011.pdf

Retrieved on: Jan. 5, 2017
4. O. Genc, M. Bayrak and E. Yaldız, "Analysis of the effects of GSM bands to the electromagnetic pollution in the RF spectrum," Prog. Electromagn. Res. PIER, vol. 101, pp. 17- 32, 2010. DOI: 10.2528/PIER09111004

5. S. Miclaus and P. Bechet, "Estimated and Measured values of the Radiofrequency Radiation Power Density around Cellular Base Stations," Rom. J. Phys., vol. 52, no. 3-4, pp. 429 - 440, 2007.

Retrieved from:

http://www.nipne.ro/rjp/2007_52 34/0429 0441.pdf Retrieved on: Jan. 5, 2017

6. L. Seyfi, "Measurement of electromagnetic radiation with respect to the hours and days of a week at $100 \mathrm{kHz}-3 \mathrm{GHz}$ frequency band in a Turkish dwelling," Measurement, vol. 46, no. 9, pp. $3002-$ 3009, Nov. 2013.

DOI: 10.1016/j.measurement.2013.06.021

7. P. Baltrenas and R. Buckus, "Measurements and analysis of the electromagnetic fields of mobile communication antennas," Measurement, vol. 46 no. 10, pp. 3942 - 3949, Dec. 2013. DOI: 10.1016/j.measurement.2013.08.008

8. M. Koprivica, V. Slavkovic, N. Neskovic, A. Neskovic, "Statistical Analysis of Electromagnetic Radiation Measurements in the vicinity of GSM/UMTS Base Station Installed on Buildings in Serbia," Radiation Protection Dosimetry, vol. 168, no. 4, pp. 1 - 14, Jul. 2015. DOI: $10.1093 / \mathrm{rpd} / \mathrm{ncv} 372$ PMid: 26231558

9. T. Karadag, M. Yüceer and T. Abbasov, "A Large-Scale Measurement, Analysis And Modelling of Electromagnetic Radiation Levels in the Vicinity of GSM/UMTS Base Stations in an Urban Area," Radiation Protection Dosimetry, vol. 168, no. 1, pp. 1 - 14, Jan. 2016.

DOI: $10.1093 / \mathrm{rpd} / \mathrm{ncvoo} 8$

PMid: 25693600

10. "ICNIRP Guidelines for Limiting Exposure to TimeVarying Electric, Magnetic, and Electromagnetic Fields (up to 300GHz)," Health Physics, vol. 74, no. 4. pp. $494-522,1998$

Retrieved from:

http://www.icnirp.org/cms/upload/publications/ICN IRPemfgdl.pdf

Retrieved on: Jan. 5, 2017

11. Bilgi Teknolojileri ve İletişim Kurumundan. (9 Ekim 2015). Sayı 29497 Elektronik haberleşme cihazlarindan kaynaklanan elektromanyetik alan siddetinin uluslararasi standartlara göre maruziyet limit değerlerinin belirlenmesi, kontrolü ve denetimi hakkinda yönetmelikte değişiklik yapilmasina dair yönetmelik. (Information and Communication Technologies Authority of Turkey. (Oct. 9, 2015). Law no. 29497 Ordinance change on By-Law on Determination, Control and Inspection of the Limit Values of Electromagnetic Field Force from The Electronic Communication Devices According to International Standards.)

Retrieved from:

http://www.resmigazete.gov.tr/eskiler/2015/10/2015 1009-2.htm

Retrieved on: Jan. 5, 2017

12. PMM 8053B Field Probes Catalog, Narda Safety Test Solutions, Pfullingen, Germany.

Retrieved from:

http://www.pmm.eu/includes/sendfile.asp?nomep=

Field Probes

Retrieved on: Feb. 2, 2017 